\title{
Immune Recognition of Heat Shock Proteins Provides a Molecular Basis for the "Hygiene Hypothesis" Linking High Prevalence of Immune Disorders to Lack of Cell Stress Eliciting Events
}

\begin{abstract}
W. van Eden
Division of Immunology, Faculty of Veterinary Medicine, Utrecht University, Yalelaan 1, 3584 CL Utrecht, The Netherlands

Correspondence should be addressed to W. van Eden, w.vaneden@uu.nl

Received 11 October 2012; Accepted 31 October 2012

Academic Editors: S. Sánchez-Ramón and A. Tommasini

Copyright () 2012 W. van Eden. This is an open access article distributed under the Creative Commons Attribution License, which permits unrestricted use, distribution, and reproduction in any medium, provided the original work is properly cited.

A modern interpretation of the hygiene hypothesis proposes the so-called "old friends" to trigger tolerogenic responses through innate receptors of dendritic cells (DC). Tolerogenic DCs would drive regulatory T-cell polarization through induction of oldfriend-specific Treg. In the tissues of the gut that are besieged by our old friends, these cells are held to produce a continuous bystander regulation. However, such local bystander regulation in the gut may be difficult to reconcile with suppression of responses to airway allergens or autoimmune antigens present in distant body tissues. Alternatively, the regulatory Tregs may be triggered through recognition of stress proteins or heat shock proteins (HSP). Microbial HSP are immunodominant and evolutionary conserved with homologs present in mammalian cells. Microbial HSP are now known to induce Tregs that crossrecognize mammalian HSP. In addition, microbial exposures, both friendly and nonfriendly, cause cell stress and, consequently, HSP upregulation in host cells. Also such upregulated HSP can activate HSP-specific Tregs that target the upregulated HSP at sites of inflammatory stress wherever in our body. Under inflammatory conditions, cell stress-associated HSP are abundant and therefore easy targets for cognate T-cell interactions. Herewith, they provide a molecular basis for the hygiene hypothesis.
\end{abstract}

\section{Basic Hygiene Hypothesis: Atopic Diseases}

The hygiene hypothesis was originally put forward by Strachan [1] and it was meant to provide an explanatory interpretation of the rising prevalence of atopic diseases in Western countries. While hay fever had been already suggested being a so-called "postindustrial revolution epidemic" [2], Strachan analyzed household sizes in relation to childhood eczema and hay fever. The declining family size in combination with hygiene-based reduction of crossinfections in young families was suggested to explain the rise of these atopic conditions [1].

The immunological basis of the hygiene hypothesis was sought in the balance of the Th1/Th2 counteracting Tcell subpopulations [3]. Whereas Th1 cells produce proinflammatory cytokines, Th2 cells, also called true helper cells inducing antibody responses in B cells, are known to produce atopy-associated cytokines IL5 and IL13 and to provide the help for IgE producing B cells. It is known that the immature immune system of the newborn features a Th2 dominance, which gradually shifts to a more balanced Th1/Th2 equilibrium probably under the influence of microbial exposures. The assumption in the original hygiene hypothesis was that the reduced microbial exposure led to a lasting Th2 dominance, preparing the grounds for an atopic constitution.

\section{Modern Hygiene Hypothesis: Immune Disorders}

Besides the rising prevalence ofatopic conditions in Western countries, also other immune disorders have shown such 
rises over recent decades. Type I diabetes mellitus in children has become very prevalent, especially in Scandinavian countries. Also other diseases, such as multiple sclerosis and inflammatory bowel diseases, have increased [4]. Developments in the immunological understanding of T-cell regulation and in particular the characterization of the regulatory $\mathrm{T}$ cell (Treg) has led to a broader interpretation of the hygiene hypothesis, which now tends to comprise all manifestations of immune dysregulation. There is good evidence that Tregs are always implicated in infection and inflammation, and therefore it is possible that the development or tuning of Treg activities depends on microbial exposures, herewith widening the impact of hygiene from atopy to immune dysregulation more in general.

\section{Microbial Exposures That Impact Immune Balance: The "Old Friends" Idea}

By now there has been produced a vast epidemiological literature on attempts to analyze infection or other microbial exposures in relation to allergies and other immune disorders. Inevitably, this has yielded conflicting findings and it has led to widely debated controversies. Nonetheless, at this moment there is no better explanation for the impressive rise in immune-associated disease prevalence than the hygiene theory. As stated by Strachan, more recently, the hygiene hypothesis remains a credible but nonspecific explanation for observed variations over time, place, and person at risk for developing atopic allergic disorders. More prospective studies are needed to unravel which infectious agents exert a protective effect and time period of importance for sensitization. The clinical implications of these advances in understanding the etiology of atopic allergic disorders are currently limited [5]. Despite the fact that clinical implication can be currently limited, the hygiene hypothesis aroused much interest and debate as it tended to affect health in a broad sense. Hygiene was held to produce widely prevalent nasty conditions such as allergies and its severe consequences such as asthma. In addition, it produced chronic severely debilitating and even lethal conditions such as diabetes, RA, and MS.

One of the issues here is vaccination. Currently vaccines are widely used in healthy individuals mostly at a young age. The purpose of vaccination is, in most cases, the prevention of childhood diseases. As a consequence, many studies of hygiene levels and allergies or autoimmunity have focused on these childhood diseases and childhood vaccination campaigns. Despite minor trends that were reported in some studies, the overall outcome of such studies showed that there are no specific effects of particular childhood vaccines on immune disorder prevalence, as summarized in Koppen et al.'s study [6]. In addition, possibly with exception of hepatitis A virus infections [7], no firm epidemiological evidence was found for an inverse relationship between childhood infectious diseases and allergies or other immune disorders.

If childhood infectious diseases for which we have vaccines are not critical determinants in the hygiene problem, what other source of microbial exposures could possibly play their role? Household hygiene has been studied and was found not to have measurable impact [8]. For body hygiene, as far as it was studied, again no measurable effects were reported. Interestingly, however, as discussed by Whitlock and Feelish [9] and Rook [10], we can be almost sure that modern soaps and detergents have modified our skin flora by eliminating ammonia-oxidizing bacteria, resulting in a neutropenic skin. Given the fundamental role of $\mathrm{NO}$ in immunoregulation, this could have affected our immune system.

Graham Rook has reasoned from an evolutionary point of view [10]. Any organism that has been consistently present for a significant part of mammalian evolution might have "written into" the mammalian genome. In other words, our environmental exposure to such organisms must have led to a "Darwinian" adaptation of our evolving immune system. There are good reasons to believe that the contrived absences of these so-called "old friends" must be implicated in the negative effects of improved hygiene that we start to see nowadays. Examples of such old friends could well be saprophytic mycobacteria, multiple helminths, some gut microbiota, hepatitis A virus, Helicobacter pylori, Salmonella, Toxoplasma, and fermenting lactobacilli. Our "old friends" are microorganisms associated with farms, untreated water supplies, cowsheds, pets, fermented foods, and have been part of the human microbiological environment for millennia. Such "domestic" commensals are, however, mostly depleted in the westernized environment [3].

There is a vast array of literature on the immunoregulation-inducing effects of helminths. Some clinicianinvestigators have started to exploit helminths such as Trichinella suis for the immunological intervention in chronic inflammatory diseases. Summers et al. has pioneered the use of oral live Trichinella in patients with inflammatory bowel diseases, and also more recently allergies [11]. Pritchard et al. have started to test hookworm (Necator americanus) in phase I clinical trials in allergic rhinoconjunctivitis and have plans to move to MS and IBD [12, 13]. Also live mycobacteria in the form of BCG have shown their immunomodulatory diabetes inhibiting effects not only in models of type I diabetes [14] but also recently in humans [15].

\section{The Immune Mechanisms of the Hypothesis Revisited}

Since the original balance in the adaptive immune system at the level of Th1 and Th2 T cells was proposed as the critical factor in the immune system leading to raised allergy proneness, scientific advances were made with discoveries in the innate arm of the immune system. The significance of the innate immune system became especially clear when dendritic cells (DCs) and Toll-like receptors (TLRs) were surfacing as the major constituent cells and receptors of the innate immune system. The functional characterization of DCs and their various subsets led to the realization that DCs were not only perfect scavengers and presenters for antigens, 
but, in addition to this, critical regulators of the ensuing adaptive immune responses. TLRs turned out to contribute to the tuning of DC activity by their intrinsic capacity to discriminate between distinct invading microorganisms. Reasoning along the lines of the "old friends" idea, it makes a perfect sense that TLR signaling by commensals and some specific "old friends" lead to production of tolerogenic or regulatory DCs. Organisms recognized as harmless by the innate immune system for instance through patternrecognition receptors, such as CARD15 and TLR-2, cause DCs to mature into regulatory DC that drive regulatory T-cell polarization. Examples of environmental organisms that trigger regulation are the following. Mycobacterium vaccae induces a population of pulmonary $\mathrm{CD} 11 \mathrm{c}+$ cells with regulatory potential [16]. Bilharzia worms trigger TLR2 producing regulatory DC which activates IL10 producing T cells [17]. Probiotic bacteria induce IL10 producing Treg through DC-SIGN-mediated DC modulation [18]. And finally, Lipoteichoic acid (LTA) produced by commensal staphylococci of the skin have been seen to inhibit inflammatory cytokine production by keratinocytes through a TLRdependent mechanism [19].

Some of these old-friend-induced DCs will recognize the "old friends" themselves and so provide a continuous background bystander regulation. This would work only at the local level, in the vicinity of our old friends. Regulatory DCs, however, might also process and present epitopes from self-antigens, from allergens and from gut content (antigens, bacterial DNA motifs, microbial heat shock proteins) and so drive specific immunoregulation of a more systemic nature [3].

\section{Deficient Immunoregulation and Disease}

Preliminary data from animal models of autoimmunity and from patients suggest that there is a link between defective Treg cell activity and disease. In patients with multiple sclerosis, putative Treg cells have been demonstrated in peripheral blood, but their capacity to suppress potentially disease-causing effector T cells is impaired [20]. In healthy individuals, $\mathrm{T}$ cells directed against a disease-relevant islet cell autoantigen were reported to show a regulatory phenotype; however, in patients with type I diabetes these $\mathrm{T}$ cells were proinflammatory [21]. Individuals with an allergic predisposition have deficient Treg cell activity [22, 23].

A recent review of Tregs in human autoimmunity has very nicely summarized the difficult challenge of demonstrating global defects in Treg of individuals diagnosed with autoimmune diseases [24]. In summary, decreased frequencies of Treg were consistently found in SLE, whereas functional deficiencies of Treg were seen in MS and type I diabetes mellitus. In contrast, studies in patients with rheumatoid arthritis have demonstrated that functionally active Treg cells are present in peripheral blood and the synovial compartment during active disease $[23,25]$. The possible defect in RA could be in the inflammatory effector cells of the synovial cell compartment that are relatively resistant to the suppressive effect of Tregs [26]. Altogether, these data could be used to suggest that those disorders that involve defective Treg cell activity are increasing in incidence in Western societies [3].

\section{Heat Shock Proteins and the Cellular Stress Response}

Stress proteins or heat shock proteins (HSP) are evolutionary-conserved proteins present in every prokaryotic or eukaryotic cell. Their main function is to protect cells and proteins from stress-induced forms of protein damage, including damage resulting from inflammation. The discovery of mycobacterial HSP60 being a critical antigen in the model of adjuvant arthritis [27] has led to studies that showed the immunodominance of microbial HSP60 and the potential of the microbial HSP induced repertoire of antibodies and T cells to crossrecognize the self-HSP homologues of stressed cells. Since then, the research in the immunology of stress proteins started to comprise a widening spectrum of topics with potential medical relevance [28]. Interestingly, since stress proteins have their activities in both innate and adaptive immunities, they are key elements in the cross-roads between both arms of the immune system. The inducible nature of HSP is particularly evident in infection. Many features of inflammation, such as production of inflammatory mediators, cytokines such as TNF $\alpha$ and IL1, cell debris, reactive oxygen intermediates, and raised temperature are perfect inducers of heat shock protein expression. In fact, raised temperature due to fever and inflammation are key components of virtually all immune responses. The effects of raised temperature in the form of experimental hyperthermia on HSP expression, and its facilitation of many distinct forms of specific immunity, has been the subject of many studies already [29].

Being intracellular proteins, HSP do load MHC class I molecules, and induction of HSP-specific class I restricted CTL responses have been documented in many different situations of cell stress. One of the first observations was made with CTL raised against mycobacterial HSP65, as these CD8+ class I restricted T cells recognised macrophages subjected to various forms of cell stress. This was a first demonstration of the fact that HSP are processed in stressed host cells and can be presented in the context of class I molecules [30]. Besides class I, also class II molecules are loaded with HSP peptides. In fact, HSP70 peptides were prominently represented in the RP-HPLC profile of the content of class II molecules of a human lymphoblastoid cell line [31].

It is of interest to note that the loading of MHCII by intracellular stress proteins occurs especially proficient in cells under stress. In this case the routing of the intracellular cargo into the MHCII compartment is organized through autophagy [32]. Autophagy consists of a collection of intracellular routing pathways and essential homeostatic maneuvers by which cells break down their own components. Perhaps a primordial function of this lysosomal degradation pathway is adaptation to various forms of stress such as 
nutrient deprivation. In addition, in complex multicellular organisms, these pathways or autophagy proteins orchestrate diverse aspects of cellular and organismal responses to dangerous stimuli such as infection [33]. Some HSP70 family members are directly involved with one of the molecular machineries that take care of autophagy, such as the so-called chaperone-mediated autophagy [34]. This may well explain why fragments of HSP70 have been found to dominate the MHCII ligandome of both human and mouse cells $[35,36]$, especially under conditions of cellular stress.

Also for microbes, stress leads to upregulation of their stress proteins. Interestingly enough, prokaryotic cell-surface expression of stress proteins has been documented [37]. Microbes, be it safe commensals or deadly pathogens, when entering tissues or cells of their hosts, will experience stress which leads to an immediate upregulation of stress proteins.

6.1. HSP Immune Responses and Lack of Self-Tolerance. Besides their immunodominance as microbial antigens, selfHSP, when (over) expressed as self-antigens by cells or tissues, are also frequently targets of immune responses. And this may well be a peculiar feature of HSP, especially because immune responses to this self-antigen mostly are not associated with pathogenic autoimmunity. Healthy individuals have a broad repertoire of $\mathrm{T}$ and $\mathrm{B}$ cells with specificity for mammalian or self-HSP. Self-HSP-specific immunity has been seen to exist in mice, rats, humans and other species studied so far. Apparently, for T cells thymic selection ensures the selection of a repertoire of cells with cognate receptors that can recognize such proteins, despite the fact that they are omnipresent in almost every cell of our body.

The mechanism of the lack of negative selection for self-HSP is unclear. A low level of constitutive expression or a restricted tissue representation would be an obvious explanation. However, in the normal thymus HSPs are relatively abundantly expressed in the medullary epithelium [38-40] and yet fail to induce tolerance by negative selection. And also the transgenic overexpression of mouse HSP60 in the thymic cortical epithelium and bone-marrow-derived cells of NOD mice, through the mouse class II E $\alpha$ promoter, did not eliminate T-cell responses to a panel of self-HSP60 peptides, although an epitope shift with disease suppressing potential was noted [39]. Possibly, a peculiar subcellular localization characteristic for HSPs creates a threshold effect, somehow allowing for an efficient expansion of cells with low affinity receptors that thereby escape deletion.

Whatever the mechanisms behind this lack of tolerance may be, it needs to be compensated efficiently by immune regulation in the periphery in order to control self-HSspecific immunity. And indeed, as we will discuss later, immune regulatory mechanisms have been shown to be a prominent feature of HSP-specific immune responses. And here we seem to have arrived at one of the most intriguing aspects of immunity for HSPs. Their evolutionary conservation, their omnipresence in cells and tissues, and their inducible nature seem to have made HSP into very dependable self-antigens for the immune system to target regulation. For the same reason Cohen has mentioned HSP as prime examples of his so-called homuncular antigens [41]. And along similar lines of reasoning, the findings that HSP such as HSP90 are part of a subset of highly conserved and immunodominant self-antigens that are target for natural autoantibodies in normal human IgG also indicate that HSP may be essential for selection of natural B- and T-cell repertoires and for the maintenance of self-tolerance [42].

\section{The Immunoregulatory Effects of Stress Proteins}

We obtained initial evidence for a role of HSP in autoimmunity when working with the adjuvant arthritis model. This model was coincidentally discovered by Pearson in the 1950s, when he immunized rats using heat killed mycobacteria in oil as an adjuvant [43]. On the basis of the histology of affected joints, adjuvant arthritis was characterized as a model for chronic rheumatoid arthritis in humans and its nature as a T-cell-mediated autoimmune condition was established through the successful transfer of disease into naïve recipient rats with $T$ cells obtained from diseased animals. These transfer studies were refined later by Holoshitz et al. when they succeeded in transferring disease into irradiated Lewis rats with a T-cell clone, called A2b, obtained from mycobacteria immunized animals and having specificity for an unknown M. tuberculosis antigen [44].

\subsection{Mycobacterial HSP60 Discovered as a Critical Antigen} in Adjuvant Arthritis. The exact nature of the arthritogenic mycobacterial antigen was discovered when we tested a $60 \mathrm{kDa}$ recombinant mycobacterial antigen, obtained through molecular cloning by van Embden. T cell A2b showed a vigorous proliferative response in the presence of this antigen, which even exceeded the level of responsiveness towards its original antigen, crude mycobacteria [27]. Analysis of the gene sequence coding for this antigen revealed its nature: it was a member of the HSP60 family of bacterial heat shock proteins. This finding of a conserved bacterial HSP as the antigen for arthritis producing $\mathrm{T}$ cells in the adjuvant arthritis model triggered a wide search for HSP immune reactivity in other disease models and in human autoimmune diseases. For obvious reasons, these studies were initiated with the idea that self-HSPs were possibly the long-sought autoantigens with a broad significance to autoimmunity in general. And, indeed, autoreactivity to HSP has been found in almost every human autoimmune condition studied, as we will discuss later. The actual disease causing T-cell epitope of A2b in mycobacterial HSP60, the sequence 180-188 of mycobacterial HSP60, was however not conserved. And, as therefore expected, disease producing T cell A2b did not respond to rat HSP60. Thus, the T cell that had defined HSP as an antigen critical to disease did not have the self-homologous HSP as a target autoantigen [27].

In addition to this, despite the fact that HSP60 was the mycobacterial antigen that stimulated the arthritis producing capacity of $\mathrm{T}$ cell $\mathrm{A} 2 \mathrm{~b}$ in adjuvant arthritis, when the mycobacterial HSP60 molecule was isolated from the context of the entire mycobacterium and used to immunize, no 
disease developed. Interestingly however, immunization was seen to lead to resistance to subsequent disease induction instead [27]. This was also found in a similar model in Lewis rats, where disease was induced with a fully synthetic nonantigenic compound known as avridine or CP20961 and which does not contain any microbial constituents [45, 46]. And herewith, it became clear that unexpectedly the protective effect of mycobacterial HSP60 in adjuvant arthritis was not dependent on antigenic relationships between the disease inducing and the protective antigen.

\subsection{HSP Induce Protection in Mouse and Rat Arthritis Models.} Subsequent experiments carried out in various experimental models have now further substantiated the arthritis inhibitory effect of mycobacterial HSP60 immunisation. This was the case for streptococcal cell wall induced arthritis in rats [47], adjuvant arthritis in rats [45], pristane induced arthritis in mice [48] and to some extend collagen induced arthritis in rats [46]. Ragno et al. have shown the protective effect of mycobacterial HSP60 as a naked DNA vaccine in adjuvant arthritis [49].

Several studies now also have shown the protective effects of mycobacterial HSP60-derived peptides in adjuvant arthritis [50-52]. Besides nasal administration of peptide, oral administration of mycobacterial HSP60 has been successful [53]. Studies on the potential of repetitive oral administration of mycobacterial HSP60 to suppress adjuvant arthritis, have revealed that in the presence of soy-been trypsin inhibitor, very low dosages of HSP60 (30 $\mu \mathrm{gr})$ can suppress disease. The oral administration, by gastric gavage, was also effectively suppressing disease, when the procedure was started at the time of already clinically overt disease [54]. In the absence of soy-been trypsin inhibitor the disease suppressive effect could be potentiated by coadministering orally the beta2-adrenergic agonist salbutamol [55]. Also other HSP family members were tested and found to inhibit experimental arthritis. In rat adjuvant arthritis this was done with HSP10, and the protective effect was seen for mycobacterial HSP10 and not for the E. coli HSP 10 (GroES) or the rat HSP10 [56]. For mycobacterial HSP70, disease prevention by prior HSP immunization was seen in rat adjuvant arthritis, avridine arthritis, and to a lower extent collagen II arthritis $[46,57]$. Recently, we also have seen preventive effects in a mouse $(\mathrm{Balb} / \mathrm{c}$ ) model of aggrecaninduced model using preimmunisation with mycobacterial HSP70 in DDA as an adjuvant [58].

In an elegant study, Tanaka et al. showed that Listeria monocytogenes infections in Lewis rats activated $\mathrm{T}$ cells directed against the HSP70 234-252 sequence, conserved between mycobacterial and Listeria HSP70. The T cells responding to this peptide suppressed inflammatory responses against listerial infection and produced IL10. The findings made were compatible with a scenario where $\mathrm{T}$ cells recognizing this HSP70 epitope were involved in terminating Th1-mediated excessive inflammation after "the battle against $L$. monocytogenes has been won." The same (mycobacterial) HSP70 peptide upon immunization prevented the development of adjuvant arthritis and this effect was inhibited by the administration of anti-IL10 antibodies [59].

Wendling defined several other T-cell epitopes in mycobacterial HSP70 in Lewis rats. One of these peptides, HSP70 111-125, was found to stimulate production of IL10 in responding $\mathrm{T}$ cells. Upon nasal administration, the 111125 peptide was found to prevent the subsequent induction of adjuvant arthritis [60].

\subsection{Microbial HSP and Disease Suppression in Nonarthritic} Inflammatory Disease Models. In NOD diabetes the effects of mycobacterial HSP60 have been found to vary with the manner of their administration [61]. In PBS, mycobacterial HSP60 was found to inhibit disease development and in IFA it induced more rapid diabetes. The spontaneous onset of beta cell destruction went together with the development of antimycobacterial HSP60 T cells, the release of self-HSP60 in the blood and the subsequent production of anti-HSP60 antibodies. These studies have led to a further analysis of the mouse HSP60 and especially the p277 peptide of HSP60 in NOD diabetes [62]. These studies have led to a recent very successful phase III clinical trial in type I diabetes with the peptide called DiaPep277. HSP60 peptide DiaPep277 showed immunomodulatory effects in diabetes type I patients leading to a reduced need for insulin suppletion in these patients [63]. From the analysis in NOD mice it seems that HSP60 may have a unique function in beta cells and in the destructive process of type I diabetes [64].

In agreement with this were our findings that in NOD and in genetically protected NOD-asp mice, the development of insulitis was characterised by the in vivo priming of mycobacterial or human HSP60 responsive T cells that produced IL10 upon in vitro restimulation with HSP60. This was not seen in control mice without developing insulitis. Apparently, expression of endogenous HSP60 in insulitis was associated with the regulation of insulitis [65]. When administered at a high dose, also the nonmicrobial HSP gp96 was found to suppress diabetes in NOD mice [66].

Other studies have indicated that, intracellularly, HSP may play a role in protecting beta cells. For HSP70 a role as a molecule involved in cellular repair in diabetes was postulated, when it was shown that (heat stress) induction of endogenous HSP70 in islets was impaired in diabetes prone $\mathrm{BB}$ rats at a young age but also at the older diabetes sensitive age [67].

Ample attention was given to the possible role of microbial HSP60 in atherosclerosis. Initially, HSP60 was seen as antigen with a disease initiating or perpetuating role. This was based on evidence in humans that the presence of antibodies to Chlamydia HSP60 was associated with developing atherosclerosis and that in rabbits immunizations with mycobacterial HSP60-induced disease [68-71]. In a recent study the presence of autoreactive HSP60-specific T cells in early human atherosclerotic lesions was documented [72]. Now, however, various studies have shown the potential of microbial HSPs to suppress disease. Maron et al. showed in atherosclerosis prone LDL receptor knockout mice, which were fed with high-cholesterol diet, that nasal administration 
of mycobacterial HSP60 caused a decrease of atherosclerotic plaques in the aortic arch [73]. The reduction of the size of the plaques was accompanied by a reduction of macrophagepositive areas and increased expression of IL10 in the plaques. In the experimental model, Harats et al. studied oral tolerance induced with mycobacterial HSP60. In this case early atherosclerosis was attenuated and the effect seemed mediated by IL4 [74]. Very similar results were obtained by Van Puijvelde et al. in a model of atherosclerosis in LDL receptor knockout mice on a high-cholesterol diet, where a collar is placed around the carotis artery. In this model low dose oral mycobacterial HSP60 caused a dramatic drop in the size of plaques developed. A very similar effect was seen after the oral administration of a mycobacterial HSP60-derived peptide that comprised a previously mapped T-cell epitope, indicating that the effect on plaque sizes was T-cell mediated [75].

The critical role of inflammation in atherosclerosis is now widely accepted. Apart from oxidized LDL, microbial HSP60 is now one of the major antigens known to be implicated in the inflammatory process of atherosclerosis. Having such an antigen, vaccination against atherosclerosis may have become an appealing option [76].

\section{Mechanisms of Immunoregulatory T-Cell Induction}

As for other antigen-specific immune responses, adaptive immune responses to HSP will depend for both their initiation and the development of particular effector mechanisms, on the signals provided by the innate immune system [77]. Given the variety of cells involved in innate immune responses and the variety of innate HSP receptors discovered so far [78], one may conclude that innate responses to HSP exist and prepare the ground for finely tuned adaptive responses to these ubiquitous proteins. In other words, likely enough the quality of the adaptive response will be determined by the circumstances, as noticed by the elements of the innate immune system.

In the literature many studies have reported and emphasized the proinflammatory effect of heat shock proteins. Some of the experimental findings however were based on in vitro effects obtained with recombinant proteins contaminated with LPS or other bacterial compounds. By Henderson et al. this issue has been discussed and it was concluded that in some cases proinflammatory effects of HSP must be real [79]. Nonetheless, in a recent review we have discussed the issue again and we argued that the default reactivity triggered by heat shock proteins is regulation, despite the sometimes observed proinflammatory effects of HSP [80].

Relevant in this case, TLR2 and TLR4 signalling is associated with not only production of Th1 cytokines in DC, but also the induction of IL10 [81, 82]. Chlamydia HSP60 has been shown to induce IFN $\gamma$ and IL10 in lymphocytes obtained from women that have experienced Chlamydia infections [83]. Also the heat shock response in cells has been noted to produce LPS-induced IL10 production and to suppress LPS induced IL12 production [84]. This latter finding is in accordance with the suggestion that IL10 is in fact a stress cytokine produced not only in response to microbial pathogens but also to cellular injuries of diverse origin [85].

The connection between TLR triggering and induction or expansion of regulatory $\mathrm{T}$ cells has been elucidated in a diverse set of experimental approaches. TLR4 turned out to be present on Treg and triggering through LPS produced expansion of Treg [86]. By others, the TLR2 ligand Pam3Cys, but not LPS (TLR4) or CpG (TLR9), was found to directly act on purified Tregs in a MyD88-dependent fashion. Moreover, when combined with TCR stimulation, TLR2 triggering augmented Treg proliferation in vitro and in vivo and resulted in a temporal loss of the suppressive Treg phenotype in vitro by directly affecting Tregs [87]. A similar finding was made for TLR2 and the Treg suppressive function enhancing effect of mammalian HSP60 [88]. The peptide DiaPep277 used in the recently so successful phase III clinical trial in type I diabetes was also known to interact with TLR2 [63]. In a murine skin transplant model mycobacterial HSP70 was found to produce regulatory $\mathrm{T}$ cells which prolonged skin graft survival, mediated through the inhibition of DC maturation $[89,90]$.

\subsection{Microbial HSP Trigger Self-HSP Cross-Reactive Regulatory} T-Cell Responses. Anderton has analysed the protection in the Lewis rat adjuvant arthritis model that resulted from immunization with mycobacterial HSP60 [27]. He tested lymphocytes obtained from such protected rats and monitored T-cell responses to an overlapping set of 15mer peptides spanning the complete mycobacterial HSP60 sequence. Nine distinct dominant T-cell epitopes were discovered. In extensive adoptive transfer studies, using Tcell lines generated to all epitopes, he discovered that only $\mathrm{T}$ cells directed to a very conserved 256-265 sequence transferred protection into naïve animals [50]. The latter $\mathrm{T}$ cells were shown to recognize the tissue or rat HSP60 homologous peptides and also heat shocked autologous spleen cells. Furthermore, active immunization with the conserved mycobacterial peptide protected against the induction of both mycobacteria-induced adjuvant arthritis and avridineinduced arthritis. All other peptides encomprizing Lewis rat HSP60 T-cell epitopes failed to produce such protection. In other words, of all epitopes analysed, only the epitope that was conserved to the extent that it induced self-HSP crossreactive $\mathrm{T}$ cells was able to fully protect.

This mechanism of mycobacterial HSP60 mediated suppression of arthritis through a conserved microbial HSP sequence, has been reproduced very similarly for mycobacterial HSP70 by others [51, 59] and ourselves [60]. Also, in these latter cases $\mathrm{T}$ cells recognizing the very conserved mycobacterial HSP70 peptides were found to produce protection, and the other nonconserved peptides were not. The mechanisms of HSP-induced T-cell regulation was already reviewed in Van Eden et al. [91]. 


\section{Tregs Induced by Cellular Stress Proteins}

As mentioned above, fragments of stress proteins, such as HSP70 family members, are frequent and relatively abundant in the MHCII ligandome of cells and stressed cells in particular. This means that HSP epitopes are well represented on cells poised for presenting their internal cargo to $\mathrm{T}$ cells.

Regulatory $\mathrm{T}$ cells are for their function dependent on triggering through their TcR. This means that Tregs work in an antigen-specific manner. The obvious question then is, which antigens are target for Tregs. In the case of autoimmune diseases, autoantigens could possibly serve as targets for such antigen-specific Tregs. However, it is questionable whether the typical autoantigens associated with autoimmune diseases are sufficiently abundant to serve as targets in this case. In general we may assume that in polyclonal populations of Tregs a great diversity of TcRs will be represented and that only a minor fraction of these Tregs will have a TcR with specificity for one of the autoantigens that is present. In other words, for a functional Treg mediated suppression we may assume that only very abundant self-antigens may serve as targets for Treg mediated suppression [92]. Evidently, stress proteins are abundant self-antigens, which are omnipresent and recognized by cells of the immune system on a regular basis. Whenever stress is imposed on cells of our body, the full spectrum of stress proteins will become upregulated and preferentially uploaded in MHC and exposed for T-cell recognition.

That such exposed stress protein fragments may be targeted by Treg was demonstrated recently by Van Herwijnen et al. [36]. A conserved mycobacterial HSP70 peptide was found to have the capacity to induce a very potent regulatory T-cell response. Due to its conservation, various self-homologs with amino acid sequences almost identical with B29 were identified in the mammalian HSP70 family members. Interestingly, the mammalian B29 homologs were also found to be present in human HLA-DR4 molecules obtained from stressed B cells [35]. Following immunization with this HSP70 peptide, which is called B29, responding spleen lymphocytes were selected by cell sorting for regulatory $\mathrm{T}$ cells on the basis of $\mathrm{CD} 4+\mathrm{CD} 25+$ Foxp3 3 expression. By adoptive transfer of these sorted Tregs we found that these cells had a remarkable capacity to suppress disease. The latter was shown in an experimental model of autoimmunity, proteoglycan induced arthritis. By the in vitro restimulation of the B29 induced Treg with the mammalian homolog's, the upregulation of Treg-associated activation markers was seen, indicating that indeed the mammalian homologs were in vivo targets of these Tregs.

In summary, we have identified peptide B29 as an evolutionary conserved Hsp70 epitope with homologues abundantly present in human and mouse MHC class II molecules. T cells recognizing B29 and these homologues were found to be strongly disease suppressive and characterized by CD25+Foxp3+LAG3+ expression. Exceptionally low numbers of these cells, up to as few as 4000 cells, were capable of preventing induction of disease and of suppressing already established disease. These cells were long-lived and found to reside in the joints and draining lymph nodes. In vivo depletion of disease suppressive Tregs, using an antibody that recognized a congenic marker on the transferred $\mathrm{T}$ cells, resulted in disease flare-up [36].

\section{Cell Stress, Heat Shock Proteins, and the Molecular Basis of the Hygiene Hypothesis}

In mechanistic terms, the immunological basis of the hygiene hypothesis shifted from a Th1/Th2 disbalance and to deficient Treg activity. As discussed above, such deficient tuning of Treg would explain a rising prevalence of not only allergy but also autoimmune diseases.

It is known that Tregs can be triggered in the wake of infection. As a matter of fact, innate TLR triggering by several microbial PAMPs is proposed to prepare grounds for expanding Treg populations. In part this may be due to the presence of TLRs on Treg, as it has been shown for example for TLR4, explaining the expansion of Tregs by LPS stimulation [86]. In the case of Pam3Cys, TLR2 triggering also led to expansion of Treg [87]. TLR2 triggering by the yeast zymosan can prepare DCs for the induction of a regulatory T-cell response [93]. The question in this case of infection, is what to expect from such expanded Tregs. Most likely, the antigen specificity of these Treg populations is related to the particular infecting microorganisms and not to allergens or autoantigens. And if so, infection may contribute to Treg expansions but it remains to be understood how such Tregs could possibly impact the diseases implicated in the hygiene hypothesis.

A unifying possibility would be the stress proteins upregulated at sites of infection. At the site of infection, the mediators of inflammation will cause stress at the level of invading infectious organisms and host cells at the same time. Given their exceptionally high levels of evolutionary conservation, the responding $\mathrm{T}$ cells will become confronted with a mixture of conserved HSP-derived peptide sequences from both exogenous and endogenous origins.

When this leads to the triggering and expansion of HSP specific Tregs, we have boosted a response in T cells that may display memory characteristics in case of renewed contact with stress proteins. In other words, these Tregs may effectively suppress the inflammation produced by allergy and autoimmunity.

Therefore, the locally enhanced expression levels of HSP, both from microbial and self-origins, may lead to a concerted and selective uploading of MHC molecules with HSP epitopes and subsequent triggering of HSP-specific T cell-Treg in this case-triggering. Besides this, a further expansion of such Treg populations may stem from the triggering of TLRs such as demonstrated for TLR2 and HSP60 [88].

Contact between immune system and the exogenous microbial world is maximal at the level of mucosal sites of the body, and the gut in particular. Therefore, hygiene hypothesis relevant interactions do occur most likely in the gut mucosal tissues. For helminths, Salmonella, helicobacter, Hepatitis A virus, and commensal flora, this is self-evident anyway. Rakoff-Nahoum et al. have already described the 
TLR dependent interactions of gut epithelial cells with the microbiota. The upregulated HSP70 in gut epithelial cells was TLR and commensal flora-dependent and turned out to protect the gut from experimental IBDs [94].

In addition, for probiotic bacteria, such as Lactobacillus GG (LGG-CM), the capacity to induce heat shock proteins in intestinal epithelial cells has been shown [95]. By inducing the expression of cytoprotective HSPs in gut epithelial cells, and by activating signal transduction pathways, some peptide product(s) secreted by LGG were found to produce such effects.

The localization of hygiene hypothesis relevant microbe host interactions in the gut has most likely added value, given the relative ease with which regulatory T-cell induction may take place in the gut.

On the other hand, the nature of the antigens involved, may well be decisive in determining whether or not the Treg induced may act locally or systemically. When old friend antigens are targets for the Tregs that are produced, the subsequent bystander suppression may regulate in a rather local manner. However, when HSP are targets of the Treg, then the same Treg populations will be able to regulate wherever in the body cognate interactions with inflammation upregulated HSP are possible (see Figure 1).

The hygiene hypothesis finds its basis in the assumption that relevant microbial exposures have been eliminated through hygiene measures. Such measures may have led to the elimination of many old friends, including some of a truly harmless nature. Nonetheless, the hygiene measures were taken with the purpose of reducing harmful and debilitating infectious diseases, which also included old friends such as helminths. Despite our longlasting, almost symbiotic, relationship with the latter creatures we choose to get rid of these gut inhabitants for good reasons. Without any doubt, this approach has been successful. Hygiene may have curtailed infectious diseases to even a greater extent than vaccines did. In addition we got rid of some of our not truly harmless friends. The common denominator of friendly and nonfriendly microbial invaders is the stress response that they induce in host cells located at their ports of entry. Expression of stress proteins is always induced and cognate interactions with stress protein-specific cells of the innate and adaptive immune system will occur. With the recent discovery of HSP being targeted by functionally effective Tregs, HSP may have a central role in the molecular basis of the hygiene hypothesis.

\section{Strategies to Counterbalance the Negative Immunological Effects of Improved Hygiene}

What solutions do we have to counteract the possibly growing problem of decreasing immune triggering? Is there a way to provide the right stimuli to our immune system in order to improve balance and control? To quote Bach on this: "There is a certain irony in the fact that we must now search for new ways to reproduce the infectious diseases against which we have fighting with great success over the past three decades. The challenge is an important one because of the high morbidity of allergic and autoimmune diseases" [4]. Should we reintroduce worms and mites in order to have healthy people in Western countries becoming infected again, thus providing a natural boost for their $\mathrm{T}$ cells, including Tregs? The obvious answer here is no!

A better and safer approach may be found in the further development of vaccines. Live attenuated or inactivated adjuvanted vaccines do create inflammatory responses which produce local cellular stress at the injection sites. However, our modern vaccines are more and more selected for being without the side effects of local pain and indurations. In other words, current and future vaccines tend to be devoid of substances that trigger cell stress and therefore tend to loose the immunological effects that are typical for natural infections.

The search for novel adjuvants that trigger receptors of the innate immune system may bring new possibilities for triggering relevant responses that include the activation of Tregs.

In addition to this, vaccines specifically designed to counterinflammatory diseases may be the solution. Immunotherapeutic approaches using HSP based vaccines have proved to be successful already in autoimmune inflammatory diseases, such as diabetes type I and arthritis $[63,96]$. Provided the results of further clinical trials obtained in active inflammatory diseases will remain positive, prophylactic approaches may become a reality, leading to truly preventive vaccines to counter the inflammatory diseases and allergies stemming from deficient natural immune triggering.

Finally, another attractive solution may be found in food. It is known that regular food constituents contain substances that induce stress responses in cells. One of the characteristics of the cellular stress response is its declining activity with ageing. In aged individuals the heat shock factor (HSF) mediated upregulation of HSPs becomes more and more impaired leading to protein folding diseases and most likely also inflammatory diseases of elderly individuals. In a search for food associated compounds which have compensating activity for the reduced stress response, we discovered carvacrol as a superb HSP coinducing moiety. Carvacrol is one of the main essential oils of Oregano species and acted on stressed cells by enhancing the expression of HSP70 only in the presence of other classical stressors, such as heat or arsenic.

When administered into mice by gastric gavage, carvacrol was found to coinduce HSP70 expression in the gut draining lymph nodes. At the same time influx of Foxp3+ CD25+ Treg was observed. When attempts were made to induce arthritis in these mice with proteoglycan injections, no arthritis was found. In adoptive transfer studies, selected CD4+ T-cell populations were collected from oral carvacrol treated mice, and transferred into naïve recipients. The transferred $\mathrm{T}$ cells fully prevented the induction of proteoglycan arthritis in the latter recipients [97].

Given the fact that the concern about the increasing prevalence's of chronic autoimmune inflammatory diseases and allergies in the Western countries is increasing and that easy solutions are not available or around the corner, the finding that a food component can boost the protective 

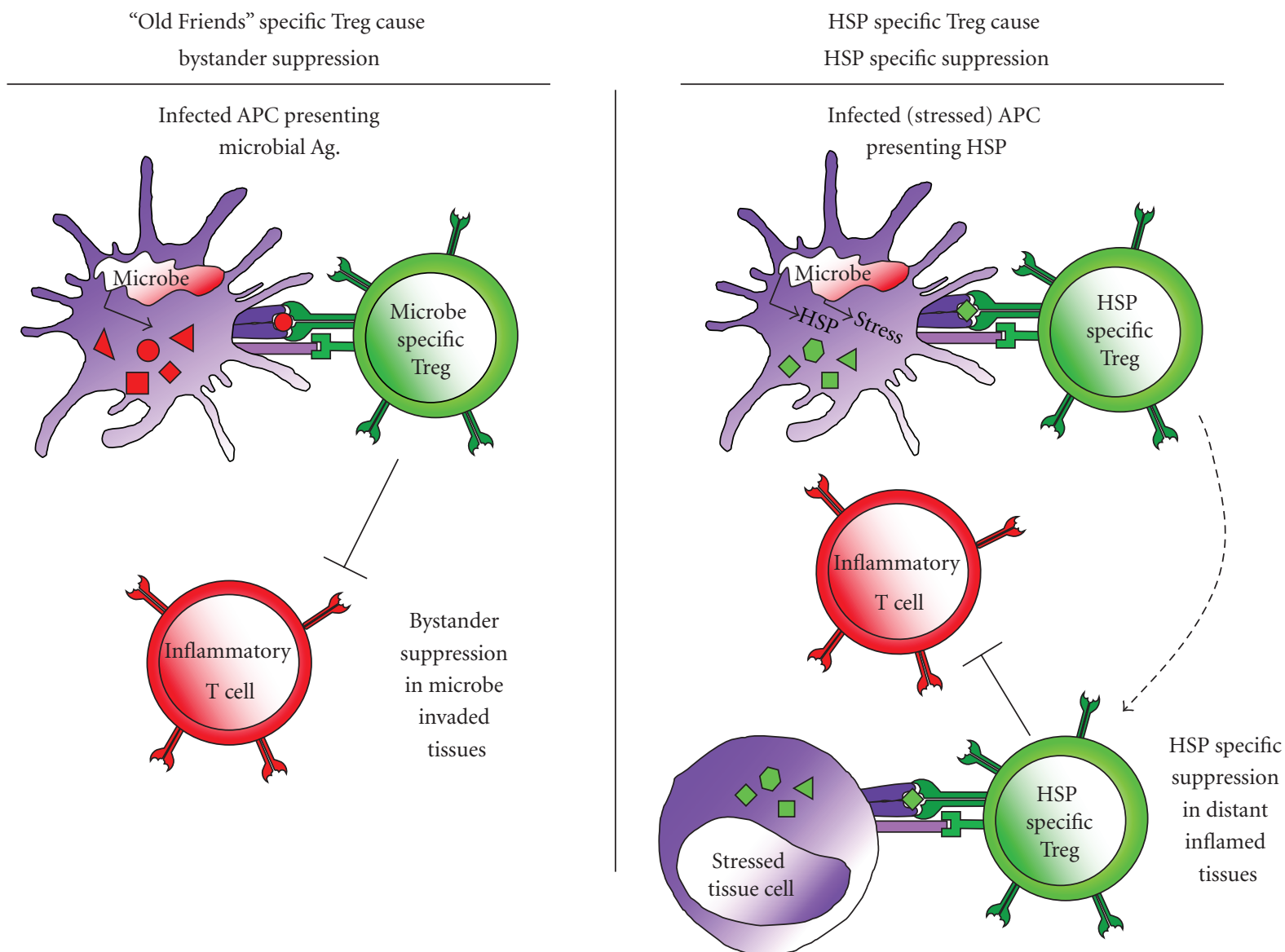

Figure 1: "Old friends" induced local bystander regulation in the gut is difficult to reconcile with suppression of responses to airway allergens or autoimmune antigens present in distant body tissues. Microbial invasion will lead to local inflammatory stress and Tregs may become induced specific for microbial antigens and for heat shock proteins expressed under influence of cellular stress. While microbe-specific Tregs will produce local bystander suppression in the vicinity of the invasive organisms, HSP specific Treg will be able to find targets for suppression wherever inflammatory stress occurs in the body. Herewith, with HSP as a molecular basis of the hygiene hypothesis, infection-induced HSP upregulation may correlate inversely with immune inflammatory disorders.

cellular response to stress and that the immune system transforms such information into regulation and suppression of inflammation seems exciting. What we eat can upregulate immune regulatory $\mathrm{T}$ cells and downregulate disease.

Healthy food is a current and modern theme. Also because of a growing epidemic of obesity and metabolic syndromes in Western countries. Therefore, the interest in the exploration of food constituents for their metabolic and immunological effects will grow with great pace. In this light, better understanding of the mechanisms that are key to the functioning of our immune system, may turn out to be essential. As argued above, the role of a fundamental and archetypical cellular event such as stress and its sequelae, should not be overlooked in this.

\section{Acknowledgments}

The author's colleague Dr. Ruurd van der Zee is acknowledged for critically reading the paper. Dr. Bram Margry is acknowledged for preparing the figure. The author received grants for his work by the Dutch Arthritis Association, the European Union Grant Seventh Framework Programme TOLERAGE: HEALTH-F4-2008-202156, and the Innovation Oriented Programme in Genomics Project Grants IGE3018 and IGE07004. The author wishes to thank Mr. Julian Oggel for his continued interest in this work.

\section{References}

[1] D. P. Strachan, "Hay fever, hygiene, and household size," British Medical Journal, vol. 299, no. 6710, pp. 1259-1260, 1989.

[2] M. B. Emanuel, "Hay fever, a post industrial revolution epidemic: a history of its growth during the 19th century," Clinical Allergy, vol. 18, no. 3, pp. 295-304, 1988.

[3] F. Guarner, R. Bourdet-Sicard, P. Brandtzaeg et al., "Mechanisms of disease: the hygiene hypothesis revisited," Nature Clinical Practice Gastroenterology and Hepatology, vol. 3, no. 5, pp. 275-284, 2006.

[4] J. F. Bach, "The effect of infections on susceptibility to autoimmune and allergic diseases," New England Journal of Medicine, vol. 347, no. 12, pp. 911-920, 2002. 
[5] A. Sheikh and D. P. Strachan, "The hygiene theory: fact or fiction?" Current Opinion in Otolaryngology and Head and Neck Surgery, vol. 12, no. 3, pp. 232-236, 2004.

[6] S. Koppen, R. De Groot, H. J. Neijens, N. Nagelkerke, W. Van Eden, and H. C. Rümke, "No epidemiological evidence for infant vaccinations to cause allergic disease," Vaccine, vol. 22, no. 25-26, pp. 3375-3385, 2004.

[7] P. M. Matricardi, F. Rosmini, L. Ferrigno et al., "Cross sectional retrospective study of prevalence of atopy among Italian military students with antibodies against hepatitis A virus," British Medical Journal, vol. 314, no. 7086, pp. 9991003, 1997.

[8] S. F. Bloomfield, R. Stanwell-Smith, R. W. R. Crevel, and J. Pickup, "Too clean, or not too clean: the Hygiene Hypothesis and home hygiene," Clinical and Experimental Allergy, vol. 36, no. 4, pp. 402-425, 2006.

[9] D. R. Whitlock and M. Feelish, "Soil bacteria, nitrite, and the skin," in The Hygiene Hypothesis and Darwinian Medicine, A. W. Graham, Ed., pp. 103-116, Birkhauser, Basel, Switzerland, 2009.

[10] G. A. W. Rook, "99th Dahlem conference on infection, inflammation and chronic inflammatory disorders: darwinian medicine and the "hygiene" or "old friends" hypothesis," Clinical and Experimental Immunology, vol. 160, no. 1, pp. 7079, 2010.

[11] R. W. Summers, D. E. Elliot, J. F. Urban, R. Thompson, and J. V. Weinstock, "Trichuris suis therapy in Crohn's disease," Gut, vol. 54, no. 1, pp. 87-90, 2005.

[12] K. Mortimer, A. Brown, J. Feary et al., "Dose-ranging study for trials of therapeutic infection with necator Americanus in humans," American Journal of Tropical Medicine and Hygiene, vol. 75, no. 5, pp. 914-920, 2006.

[13] D. Blount, D. Hooi, J. Feary et al., "Immunologic profiles of persons recruited for a randomized, placebo-controlled clinical trial of hookworm infection," American Journal of Tropical Medicine and Hygiene, vol. 81, no. 5, pp. 911-916, 2009.

[14] M. Harada, Y. Kishimoto, and S. Makino, "Prevention of overt diabetes and insulitis in NOD mice by a single BCG vaccination," Diabetes Research and Clinical Practice, vol. 8, no. 2, pp. 85-89, 1990.

[15] D. L. Faustman, L. Wang, Y. Okubo et al., "Proof-of-concept, randomized, controlled clinical trial of bacillus-calmetteguerin for treatment of long-term type 1 diabetes," PLoS ONE, vol. 7, no. 8, Article ID e41756, 2012.

[16] V. C. Adams, J. R. F. Hunt, R. Martinelli, R. Palmer, G. A. W. Rook, and L. R. Brunet, "Mycobacterium vaccae induces a population of pulmonary $\mathrm{CD} 11 \mathrm{c}+$ cells with regulatory potential in allergic mice," European Journal of Immunology, vol. 34, no. 3, pp. 631-638, 2004.

[17] D. Van der Kleij, E. Latz, J. F. H. M. Brouwers et al., "A novel host-parasite lipid cross-talk. Schistosomal lysophosphatidylserine activates toll-like receptor 2 and affects immune polarization," Journal of Biological Chemistry, vol. 277, no. 50, pp. 48122-48129, 2002.

[18] H. H. Smits, A. Engering, D. Van Der Kleij et al., "Selective probiotic bacteria induce IL-10-producing regulatory $\mathrm{T}$ cells in vitro by modulating dendritic cell function through dendritic cell-specific intercellular adhesion molecule 3-grabbing nonintegrin," Journal of Allergy and Clinical Immunology, vol. 115, no. 6, pp. 1260-1267, 2005.
[19] Y. Lai, A. Di Nardo, T. Nakatsuji et al., "Commensal bacteria regulate toll-like receptor 3-dependent inflammation after skin injury," Nature Medicine, vol. 15, no. 12, pp. 1377-1382, 2009.

[20] V. Viglietta, C. Baecher-Allan, H. L. Weiner, and D. A. Hafler, "Loss of functional suppression by $\mathrm{CD} 4{ }^{+} \mathrm{CD} 25^{+}$regulatory $\mathrm{T}$ cells in patients with multiple sclerosis," Journal of Experimental Medicine, vol. 199, no. 7, pp. 971-979, 2004.

[21] S. Arif, T. I. Tree, T. P. Astill et al., "Autoreactive T cell responses show proinflammatory polarization in diabetes but a regulatory phenotype in health," Journal of Clinical Investigation, vol. 113, no. 3, pp. 451-463, 2004.

[22] M. R. Karlsson, J. Rugtveit, and P. Brandtzaeg, "Allergenresponsive $\mathrm{CD} 4{ }^{+} \mathrm{CD} 25^{+}$regulatory $\mathrm{T}$ cells in children who have outgrown cow's milk allergy," Journal of Experimental Medicine, vol. 199, no. 12, pp. 1679-1688, 2004.

[23] U. Haddeland, A. B. Karstensen, L. Farkas et al., "Putative regulatory $\mathrm{T}$ cells are impaired in cord blood from neonates with hereditary allergy risk," Pediatric Allergy and Immunology, vol. 16, no. 2, pp. 104-112, 2005.

[24] S. A. Long and J. H. Buckner, "CD4 ${ }^{+} \mathrm{FOXP}^{+}$T regulatory cells in human autoimmunity: more than a numbers game," Journal of Immunology, vol. 187, no. 5, pp. 2061-2066, 2011.

[25] J. M. R. Van Amelsfort, K. M. G. Jacobs, J. W. J. Bijlsma, F. P. J. G. Lafeber, and L. S. Taams, "CD $4{ }^{+} \mathrm{CD} 25^{+}$regulatory T cells in rheumatoid arthritis: differences in the presence, phenotype, and function between peripheral blood and synovial fluid," Arthritis and Rheumatism, vol. 50, no. 9, pp. 2775-2785, 2004.

[26] E. J. Wehrens, G. Mijnheer, C. L. Duurland et al., "Functional human regulatory $\mathrm{T}$ cells fail to control autoimmune inflammation due to $\mathrm{PKB} / \mathrm{c}$-akt hyperactivation in effector cells," Blood, vol. 118, no. 13, pp. 3538-3548, 2011.

[27] W. van Eden, J. E. Thole, R. van der Zee et al., "Cloning of the mycobacterial epitope recognized by $\mathrm{T}$ lymphocytes in adjuvant arthritis," Nature, vol. 331, no. 6152, pp. 171-173, 1988.

[28] A. Asea and B. K. Pedersen, Heat Shock Proteins and Whole Body Physiology, Springer, 2010.

[29] E. Repasky and R. Issels, "Physiological consequences of hyperthermia: Heat, heat shock proteins and the immune response," International Journal of Hyperthermia, vol. 18, no. 6, pp. 486-489, 2002.

[30] T. Koga, A. Wand-Wurttenberger, J. DeBruyn, M. E. Munk, B. Schoel, and S. H. E. Kaufmann, "T cells against a bacterial heat shock protein recognize stressed macrophages," Science, vol. 245, no. 4922, pp. 1112-1115, 1989.

[31] J. R. Newcomb and P. Cresswell, "Characterization of endogenous peptides bound to purified HLA-DR molecules and their absence from invariant chain-associated $\alpha \beta$ dimers," Journal of Immunology, vol. 150, no. 2, pp. 499-507, 1993.

[32] V. L. Crotzer and J. S. Blum, "Autophagy and intracellular surveillance: modulating MHC class II antigen presentation with stress," Proceedings of the National Academy of Sciences of the United States of America, vol. 102, no. 22, pp. 7779-7780, 2005.

[33] B. Levine, N. Mizushima, and H. W. Virgin, "Autophagy in immunity and inflammation," Nature, vol. 469, no. 7330, pp. 323-335, 2011.

[34] S. Kaushik and A. M. Cuervo, "Chaperone-mediated autophagy: a unique way to enter the lysosome world," Trends in Cell Biology, vol. 22, no. 8, pp. 407-417, 2012. 
[35] J. Dengjel, O. Schoor, R. Fischer et al., "Autophagy promotes MHC class II presentation of peptides from intracellular source proteins," Proceedings of the National Academy of Sciences of the United States of America, vol. 102, no. 22, pp. 7922-7927, 2005.

[36] M. J. C. Van Herwijnen, L. Wieten, R. Van Der Zee et al., "Regulatory $\mathrm{T}$ cells that recognize a ubiquitous stressinducible self-antigen are long-lived suppressors of autoimmune arthritis," Proceedings of the National Academy of Sciences of the United States of America, vol. 109, no. 35, pp. 14134-14139, 2012.

[37] R. J. Du and B. Ho, "Surface localized heat shock protein 20 (HslV) of Helicobacter pylori," Helicobacter, vol. 8, no. 4, pp. 257-267, 2003.

[38] M. S. Anderson, E. S. Venanzi, L. Klein et al., "Projection of an immunological self shadow within the thymus by the aire protein," Science, vol. 298, no. 5597, pp. 1395-1401, 2002.

[39] O. S. Birk, D. C. Douek, D. Elias et al., "A role of Hsp60 in autoimmune diabetes: Analysis in a transgenic model," Proceedings of the National Academy of Sciences of the United States of America, vol. 93, no. 3, pp. 1032-1037, 1996.

[40] J. R. Ostberg, K. C. Kaplan, and E. A. Repasky, "Induction of stress proteins in a panel of mouse tissues by fever-range whole body hyperthermia," International Journal of Hyperthermia, vol. 18, no. 6, pp. 552-562, 2002.

[41] I. R. Cohen, "Biomarkers, self-antigens and the immunological homunculus," Journal of Autoimmunity, vol. 29, no. 4, pp. 246-249, 2007.

[42] A. Pashov, A. Kenderov, S. Kyurkchiev et al., "Autoantibodies to heat shock protein 90 in the human natural antibody repertoire," International Immunology, vol. 14, no. 5, pp. 453461, 2002.

[43] M. W. Whitehouse, "Adjuvant arthritis 50 years on: the impact of the 1956 article by C. M. Pearson, "Development of arthritis, periarthritis and periostitis in rats given adjuvants"," Inflammation Research, vol. 56, no. 4, pp. 133-138, 2007.

[44] J. Holoshitz, Y. Naparstek, A. Ben-Nun, and I. R. Cohen, "Lines of T lymphocytes induce or vaccinate against autoimmune arthritis," Science, vol. 219, no. 4580, pp. 56-58, 1983.

[45] M. E. J. Billingham, S. Carney, R. Butler, and M. J. Colston, "A mycobacterial $65-\mathrm{kD}$ heat shock protein induces antigenspecific suppression of adjuvant arthritis, but is not itself arthritogenic," Journal of Experimental Medicine, vol. 171, no. 1, pp. 339-344, 1990.

[46] A. E. Kingston, C. A. Hicks, M. J. Colston, and M. E. J. Billingham, "A 71-kD heat shock protein (hsp) from Mycobacterium tuberculosis has modulatory effects on experimental rat arthritis," Clinical and Experimental Immunology, vol. 103, no. 1, pp. 77-82, 1996.

[47] M. F. Van den Broek, E. J. M. Hogervorst, M. C. J. Van Bruggen, W. Van Eden, R. Van der Zee, and W. B. Van den Berg, "Protection against streptococcal cell wall-induced arthritis by pretreatment with the $65-\mathrm{kD}$ mycobacterial heat shock protein," Journal of Experimental Medicine, vol. 170, no. 2, pp. 449-466, 1989.

[48] S. J. Thompson, J. N. Francis, L. K. Siew et al., "An immunodominant epitope from mycobacterial $65-\mathrm{kDa}$ heat shock protein protects against pristane-induced arthritis," Journal of Immunology, vol. 160, no. 9, pp. 4628-4634, 1998.

[49] S. Ragno, M. J. Colston, D. B. Lowrie, V. R. Winrow, D. R. Blake, and R. Tascon, "Protection of rats from adjuvant arthritis by immunization with naked DNA encoding for mycobacterial heat shock protein 65," Arthritis and Rheumatism, vol. 40, no. 2, pp. 277-283, 1997.

[50] S. M. Anderton, R. Van Der Zee, B. Prakken, A. Noordzij, and W. Van Eden, "Activation of $\mathrm{T}$ cells recognizing self $60-\mathrm{kD}$ heat shock protein can protect against experimental arthritis," Journal of Experimental Medicine, vol. 181, no. 3, pp. 943-952, 1995.

[51] K. D. Moudgil, T. T. Chang, H. Eradat et al., "Diversification of $\mathrm{T}$ cell responses to carboxy-terminal determinants within the $65-\mathrm{kD}$ heat-shock protein is involved in regulation of autoimmune arthritis," Journal of Experimental Medicine, vol. 185, no. 7, pp. 1307-1316, 1997.

[52] R. Ulmansky, C. J. Cohen, F. Szafer et al., "Resistance to adjuvant arthritis is due to protective antibodies against heat shock protein surface epitopes and the induction of IL-10 secretion," Journal of Immunology, vol. 168, no. 12, pp. 64636469, 2002.

[53] M. A. Haque, S. Yoshino, S. Inada, H. Nomaguchi, O. Tokunaga, and O. Kohashi, "Suppression of adjuvant arthritis in rats by induction of oral tolerance to mycobacterial $65-\mathrm{kDa}$ heat shock protein," European Journal of Immunology, vol. 26, no. 11, pp. 2650-2656, 1996.

[54] P. M. Cobelens, C. J. Heijnen, E. E. S. Nieuwenhuis et al., "Treatment of adjuvant-induced arthritis by oral administration of mycobacterial Hsp65 during disease," Arthritis and Rheumatism, vol. 43, no. 12, pp. 2694-2702, 2000.

[55] P. M. Cobelens, A. Kavelaars, A. Vroon et al., “The $\beta 2-$ adrenergic agonist salbutamol potentiates oral induction of tolerance, suppressing adjuvant arthritis and antigen-specific immunity," Journal of Immunology, vol. 169, no. 9, pp. 50285035, 2002.

[56] S. Ragno, V. R. Winrow, P. Mascagni et al., "A synthetic 10$\mathrm{kD}$ heat shock protein (hsp10) from Mycobacterium tuberculosis modulates adjuvant arthritis," Clinical and Experimental Immunology, vol. 103, no. 3, pp. 384-390, 1996.

[57] B. J. Prakken, U. Wendling, R. Van der Zee, V. P. M. G. Rutten, W. Kuis, and W. Van Eden, "Induction of IL-10 and inhibition of experimental arthritis are specific features of microbial heat shock proteins that are absent for other evolutionarily conserved immunodominant proteins," Journal of Immunology, vol. 167, no. 8, pp. 4147-4153, 2001.

[58] L. Wieten, S. E. Berlo, C. B. ten Brink et al., "IL-10 is critically involved in mycobacterial HSP70 induced suppression of proteoglycan-induced arthritis," PLOS ONE, vol. 4, no. 1, Article ID e4186, 2009.

[59] S. Tanaka, Y. Kimura, A. Mitani et al., "Activation of T cells recognizing an epitope of heat-shock protein 70 can protect against rat adjuvant arthritis," Journal of Immunology, vol. 163, no. 10, pp. 5560-5565, 1999.

[60] U. Wendling, L. Paul, R. Van Der Zee, B. Prakken, M. Singh, and W. Van Eden, "A conserved mycobacterial heat shock protein (hsp) 70 sequence prevents adjuvant arthritis upon nasal administration and induces IL-10-producing $\mathrm{T}$ cells that cross-react with the mammalian self-hsp70 homologue," Journal of Immunology, vol. 164, no. 5, pp. 2711-2717, 2000.

[61] D. Elias, T. Reshef, O. S. Birk, R. Van der Zee, M. D. Walker, and I. R. Cohen, "Vaccination against autoimmune mouse diabetes with a T-cell epitope of the human $65-\mathrm{kDa}$ heat shock protein," Proceedings of the National Academy of Sciences of the United States of America, vol. 88, no. 8, pp. 3088-3091, 1991.

[62] J. Bockova, D. Elias, and I. R. Cohen, "Treatment of NOD diabetes with a novel peptide of the hsp60 molecule induces 
Th2-type antibodies," Journal of Autoimmunity, vol. 10, no. 4, pp. 323-329, 1997.

[63] S. Aldridge, "Toll-like receptor blocker slows beta cell death in type 1 diabetes," Nature biotechnology, vol. 30, no. 2, pp. 124 124C, 2012.

[64] K. Brudzynski, V. Martinez, and R. S. Gupta, "Secretory granule autoantigen in insulin-dependent diabetes mellitus is related to $62 \mathrm{kDa}$ heat-shock protein (hsp60)," Journal of Autoimmunity, vol. 5, no. 4, pp. 453-463, 1992.

[65] A. G. S. Van Halteren, B. Mosselman, B. O. Roep et al., "T cell reactivity to heat shock protein 60 in diabetes-susceptible and genetically protected nonobese diabetic mice is associated with a protective cytokine profile," Journal of Immunology, vol. 165, no. 10, pp. 5544-5551, 2000.

[66] R. Y. Chandawarkar, M. S. Wagh, J. T. Kovalchin, and P. Srivastava, "Immune modulation with high-dose heat-schock protein gp96: therapy of murine autoimmune diabetes and encephalomyelitis," International Immunology, vol. 16, no. 4, pp. 615-624, 2004.

[67] G. Wachlin, L. Heine, I. Klöting, A. Dunger, H. J. Hahn, and S. Schmidt, "Stress response to pancreatic islets from diabetes prone BB rats of different age," Autoimmunity, vol. 35, no. 6, pp. 389-395, 2002.

[68] Q. Xu, H. Dietrich, H. J. Steiner et al., "Induction of arteriosclerosis in normocholesterolemic rabbits by immunization with heat shock protein 65," Arteriosclerosis and Thrombosis, vol. 12, no. 7, pp. 789-799, 1992.

[69] G. Wick, M. Knoflach, and Q. Xu, "Autoimmune and inflammatory mechanisms in atherosclerosis," Annual Review of Immunology, vol. 22, pp. 361-403, 2004.

[70] G. Wick, H. Perschinka, and G. Millonig, "Atherosclerosis as an autoimmune disease: an update," Trends in Immunology, vol. 22, no. 12, pp. 665-669, 2001.

[71] G. K. Hansson, "Vaccination against atherosclerosis: Science or fiction?" Circulation, vol. 106, no. 13, pp. 1599-1601, 2002.

[72] G. Almanzar, R. Ollinger, and J. Leuenberger, "Autoreactive HSP60 epitope-specific T-cells in early human atherosclerotic lesions," Journal of Autoimmunity. In press.

[73] R. Maron, G. Sukhova, A. M. Faria et al., "Mucosal administration of heat shock protein-65 decreases atherosclerosis and inflammation in aortic arch of low-density lipoprotein receptor-deficient mice," Circulation, vol. 106, no. 13, pp. 1708-1715, 2002.

[74] D. Harats, N. Yacov, B. Gilburd, Y. Shoenfeld, and J. George, "Oral tolerance with heat shock protein 65 attenuates Mycobacterium tuberculosis-induced and high-fat-diet-driven atherosclerotic lesions," Journal of the American College of Cardiology, vol. 40, no. 7, pp. 1333-1338, 2002.

[75] G. H. M. Van Puijvelde, T. Van Es, E. J. A. Van Wanrooij et al., "Induction of oral tolerance to HSP60 or an HSP60peptide activates t cell regulation and reduces atherosclerosis," Arteriosclerosis, Thrombosis, and Vascular Biology, vol. 27, no. 12, pp. 2677-2683, 2007.

[76] G. K. Hansson, P. Libby, U. Schönbeck, and Z. Q. Yan, "Innate and adaptive immunity in the pathogenesis of atherosclerosis," Circulation Research, vol. 91, no. 4, pp. 281-291, 2002.

[77] A. Iwasaki and R. Medzhitov, "Toll-like receptor control of the adaptive immune responses," Nature Immunology, vol. 5, no. 10, pp. 987-995, 2004.

[78] A. Asea, M. Rehli, E. Kabingu et al., "Novel signal transduction pathway utilized by extracellular HSP70. Role of toll-like receptor (TLR) 2 and TLR4," Journal of Biological Chemistry, vol. 277, no. 17, pp. 15028-15034, 2002.
[79] B. Henderson, S. K. Calderwood, A. R. M. Coates et al., "Caught with their PAMPs down? the extracellular signalling actions of molecular chaperones are not due to microbial contaminants," Cell Stress and Chaperones, vol. 15, no. 2, pp. 123-141, 2010.

[80] W. Van Eden, R. Spiering, F. Broere, and R. Van Der Zee, "A case of mistaken identity: HSPs are no DAMPs but DAMPERs," Cell Stress and Chaperones, vol. 17, no. 3, pp. 281292, 2012.

[81] S. C. Higgins, E. C. Lavelle, C. McCann et al., "Toll-like receptor 4-mediated innate IL-10 activates antigen-specific regulatory $\mathrm{T}$ cells and confers resistance to Bordetella pertussis by inhibiting inflammatory pathology," Journal of Immunology, vol. 171, no. 6, pp. 3119-3127, 2003.

[82] M. G. Netea, R. Sutmuller, C. Hermann et al., "Toll-like receptor 2 suppresses immunity against Candida albicans through induction of IL-10 and regulatory T cells," Journal of Immunology, vol. 172, no. 6, pp. 3712-3718, 2004.

[83] A. Kinnunen, H. M. Surcel, M. Halttunen et al., "Chlamydia trachomatis heat shock protein-60 induced interferon- $\gamma$ and interleukin-10 production in infertile women," Clinical and Experimental Immunology, vol. 131, no. 2, pp. 299-303, 2003.

[84] Y. Wang, C. G. Kelly, J. T. Karttunen et al., "Cd40 is a cellular receptor mediating mycobacterial heat shock protein 70 stimulation of CC-chemokines," Immunity, vol. 15, no. 6, pp. 971-983, 2001.

[85] P. Stordeur and M. Goldman, "Interleukin-10 as a regulatory cytokine induced by cellular stress: molecular aspects," International Reviews of Immunology, vol. 16, no. 5-6, pp. 501-522, 1998.

[86] I. Caramalho, T. Lopes-Carvalho, D. Ostler, S. Zelenay, M. Haury, and J. Demengeot, "Regulatory T cells selectively express toll-like receptors and are activated by lipopolysaccharide," Journal of Experimental Medicine, vol. 197, no. 4, pp. 403-411, 2003.

[87] R. P. M. Sutmuller, M. H. M. G. M. Den Brok, M. Kramer et al., "Toll-like receptor 2 controls expansion and function of regulatory T cells," Journal of Clinical Investigation, vol. 116, no. 2, pp. 485-494, 2006.

[88] A. Zanin-Zhorov, L. Cahalon, G. Tal, R. Margalit, O. Lider, and I. R. Cohen, "Heat shock protein 60 enhances $\mathrm{CD} 4{ }^{+} \mathrm{CD} 25^{+}$ regulatory T cell function via innate TLR2 signaling," Journal of Clinical Investigation, vol. 116, no. 7, pp. 2022-2032, 2006.

[89] T. J. Borges, B. N. Porto, C. A. Teixeira et al., "Prolonged survival of allografts induced by mycobacterial Hsp70 is dependent on $\mathrm{CD} 4{ }^{+} \mathrm{CD} 25^{+}$regulatory T cells," PLoS ONE, vol. 5, no. 12, Article ID e14264, 2010.

[90] T. J. Borges, L. Wieten, M. J. van Herwijnen et al., "The antiinflammatory mechanisms of Hsp70," Frontiers in Immunology, vol. 3, article 95, 2012.

[91] W. Van Eden, R. Van Der Zee, and B. Prakken, "Heat-shock proteins induce T-cell regulation of chronic inflammation," Nature Reviews Immunology, vol. 5, no. 4, pp. 318-330, 2005.

[92] E. M. Shevach, "Mechanisms of Foxp3+ T Regulatory CellMediated Suppression,” Immunity, vol. 30, no. 5, pp. 636-645, 2009.

[93] S. Dillon, S. Agrawal, K. Banerjee et al., "Yeast zymosan, a stimulus for TLR2 and dectin-1, induces regulatory antigenpresenting cells and immunological tolerance," Journal of Clinical Investigation, vol. 116, no. 4, pp. 916-928, 2006.

[94] S. Rakoff-Nahoum, J. Paglino, F. Eslami-Varzaneh, S. Edberg, and R. Medzhitov, "Recognition of commensal microflora by 
toll-like receptors is required for intestinal homeostasis," Cell, vol. 118, no. 2, pp. 229-241, 2004.

[95] Y. Tao, K. A. Drabik, T. S. Waypa et al., "Soluble factors from Lactobacillus GG activate MAPKs and induce cytoprotective heat shock proteins in intestinal epithelial cells," American Journal of Physiology, vol. 290, no. 4, pp. C1018-C1030, 2006.

[96] E. C. Koffeman, M. Genovese, D. Amox et al., "Epitopespecific immunotherapy of rheumatoid arthritis: clinical responsiveness occurs with immune deviation and relies on the expression of a cluster of molecules associated with $\mathrm{T}$ cell tolerance in a double-blind, placebo-controlled, pilot phase II trial," Arthritis and Rheumatism, vol. 60, no. 11, pp. 32073216, 2009.

[97] L. Wieten, R. Van Der Zee, R. Spiering et al., "A novel heat-shock protein coinducer boosts stress protein Hsp70 to activate $\mathrm{T}$ cell regulation of inflammation in autoimmune arthritis," Arthritis and Rheumatism, vol. 62, no. 4, pp. 1026$1035,2010$. 


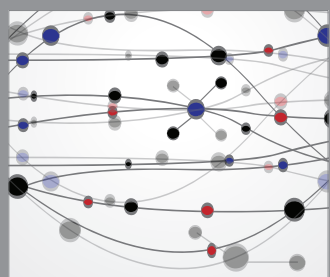

The Scientific World Journal
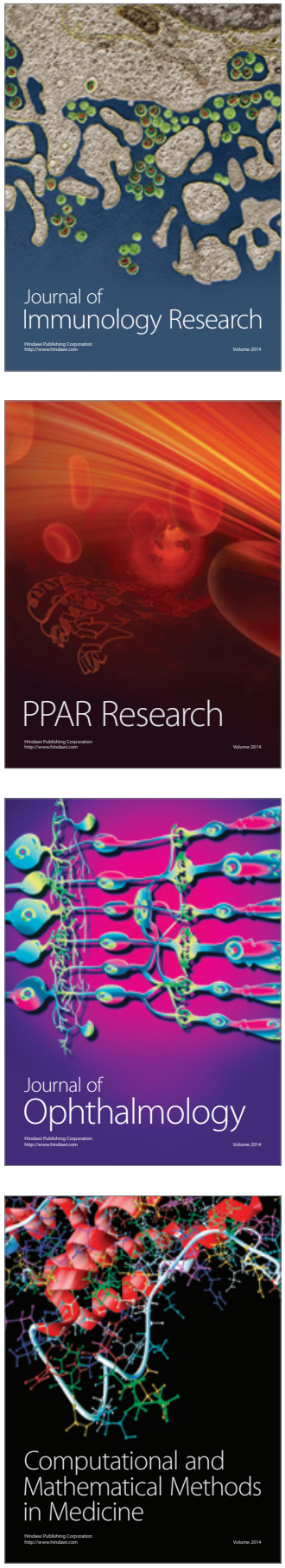

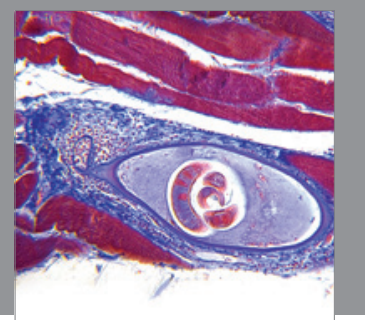

Gastroenterology

Research and Practice
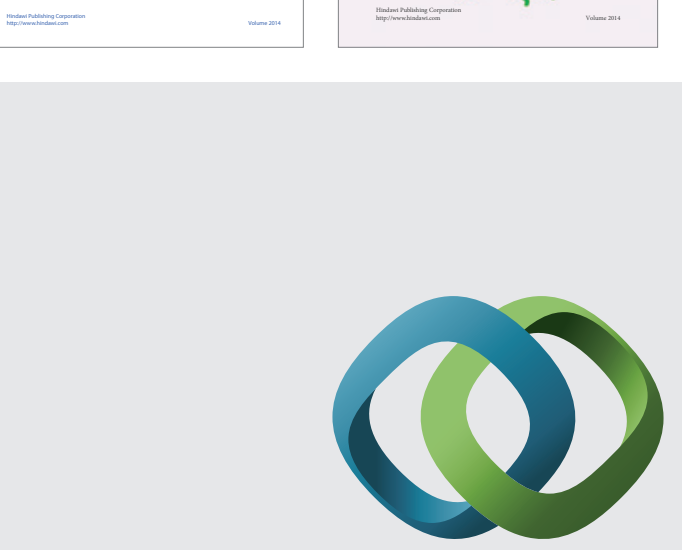

\section{Hindawi}

Submit your manuscripts at

http://www.hindawi.com
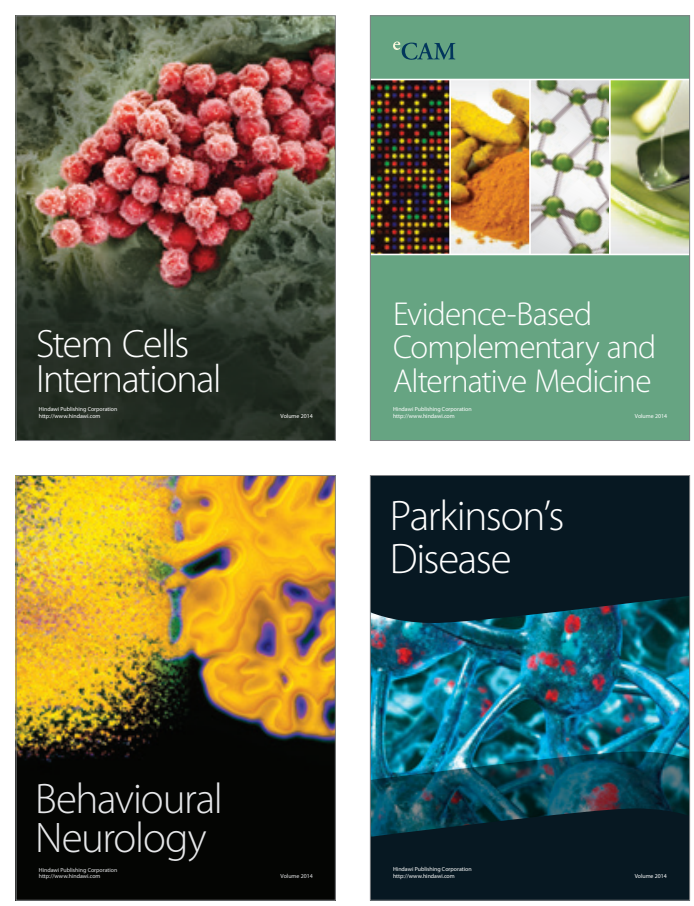

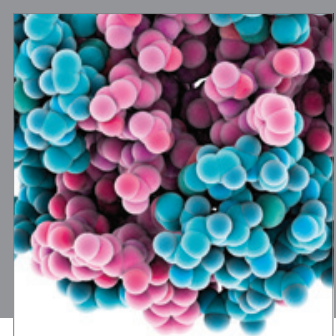

Journal of
Diabetes Research

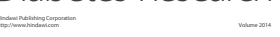

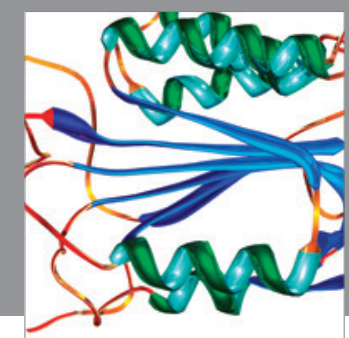

Disease Markers
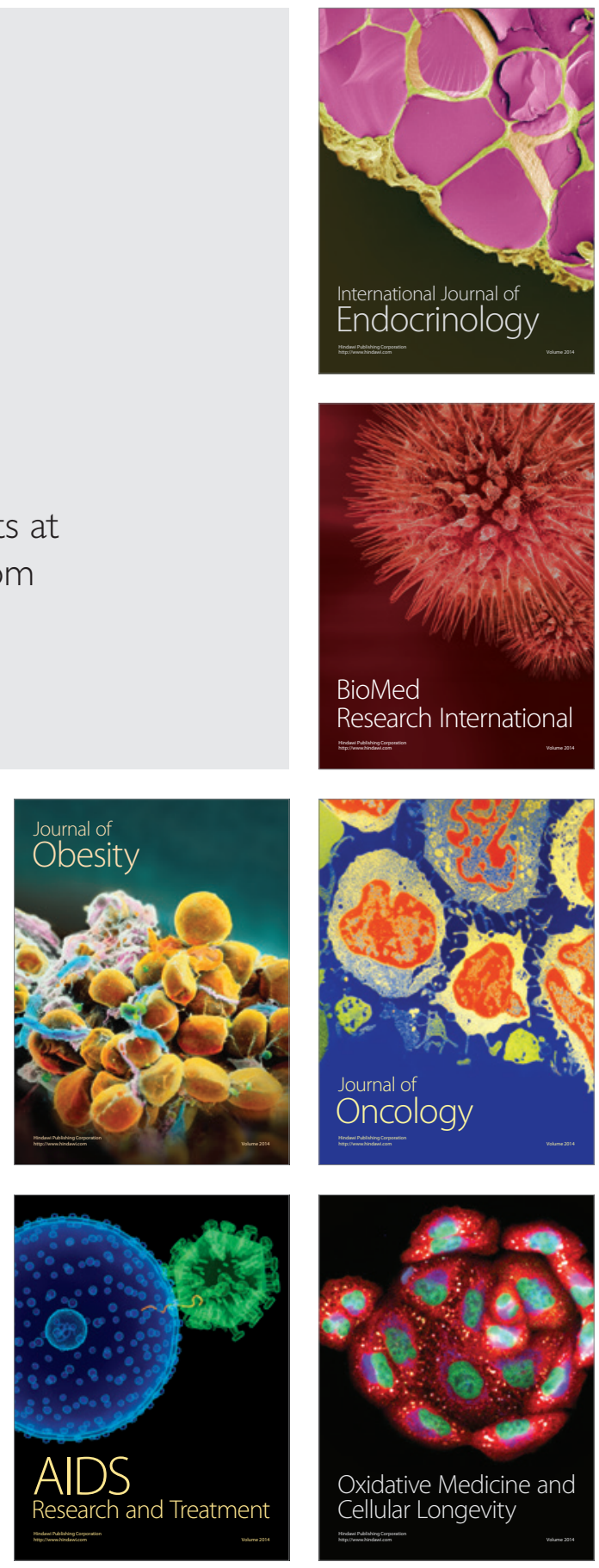